\title{
SARS-CoV-2 phase I transmission and mutability linked to the interplay of climatic variables: a global observation on the pandemic spread
}

\author{
Chidambaram Sabarathinam ${ }^{1,2} \cdot$ Prasanna Mohan Viswanathan $^{3} \cdot$ Venkatramanan Senapathi $^{4}$. \\ Shankar Karuppannan ${ }^{5}$. Dhanu Radha Samayamanthula ${ }^{1}$. Gnanachandrasamy Gopalakrishnan ${ }^{6,7}$. \\ Ramanathan Alagappan ${ }^{8} \cdot$ Prosun Bhattacharya $^{9}$
}

Received: 28 July 2021 / Accepted: 8 November 2021 / Published online: 14 January 2022

(c) The Author(s), under exclusive licence to Springer-Verlag GmbH Germany, part of Springer Nature 2021

\begin{abstract}
The study aims to determine the impact of global meteorological parameters on SARS-COV-2, including population density and initiation of lockdown in twelve different countries. The daily trend of these parameters and COVID-19 variables from February 15th to April 25th, 2020, were considered. Asian countries show an increasing trend between infection rate and population density. A direct relationship between the time-lapse of the first infected case and the period of suspension of movement controls the transmissivity of COVID-19 in Asian countries. The increase in temperature has led to an increase in COVID-19 spread, while the decrease in humidity is consistent with the trend in daily deaths during the peak of the pandemic in European countries. Countries with $65^{\circ} \mathrm{F}$ temperature and $5 \mathrm{~mm}$ rainfall have a negative impact on COVID-19 spread. Lower oxygen availability in the atmosphere, fine droplets of submicron size together with infectious aerosols, and low wind speed have contributed to the increase in total cases and mortality in Germany and France. The onset of the D614G mutation and subsequent changes to D614 before March, later G614 in mid-March, and S943P, A831V, D839/Y/N/E in April were observed in Asian and European countries. The results of the correlation and factor analysis show that the COVID-19 cases and the climatic factors are significantly correlated with each other. The optimum meteorological conditions for the prevalence of G614 were identified. It was observed that the complex interaction of global meteorological factors and changes in the mutational form of CoV-2 phase I influenced the daily mortality rate along with other comorbid factors. The results of this study could help the public and policymakers to create awareness of the COVID-19 pandemic.
\end{abstract}

Keywords COVID-19 $\cdot$ Temperature $\cdot$ Humidity $\cdot$ D614G mutation $\cdot$ Pandemic spread $\cdot$ Mortality

Responsible Editor: Lotfi Aleya

Venkatramanan Senapathi

venkatrananansenapathi@gmail.com

1 Water Research Centre, Kuwait Institute for Scientific Research, Safat, P.O. Box 24885, 13109 Kuwait City, Kuwait

2 Department of Earth Sciences, Annamalai University, Annamalai Nagar, Chidambaram, Tamilnadu, India

3 Department of Applied Geology, Faculty of Engineering and Science, Curtin University, Malaysia, CDT 250, 98009 Miri, Sarawak, Malaysia

4 Department of Disaster Management, Alagappa University, Karikudi 630003, Tamil Nadu, India

5 Department of Applied Geology, School of Applied Natural Science, Adama Science and Technology University, Adama, Ethiopia
6 School of Geography and Planning, Sun Yat -Sen University, Guangzhou 510275, People's Republic of China

7 Center for Earth, Environment and Resources, Sun Yat -Sen University, Guangzhou 510275, People's Republic of China

8 School of Environmental Sciences, Jawaharlal Nehru University, New Delhi, India

9 Department of Sustainable Development, Environmental Science and Engineering, KTH Royal Institute of Technology, Stockholm, Sweden 


\section{Introduction}

The COVID-19 pandemic is triggering a crisis that challenges the governments and health care around the world. The critical issue is to understand whether the climate factors influence the transformation of the COVID-19 pandemic. A strong correlation between climate and COVID19 was observed in Wuhan, stating that high temperatures would suppress the virus. The preliminary investigations reported that temperature and other meteorological variables, namely, humidity, air quality, and wind speed, would even affect the spread of infectious diseases. In addition, the air temperature may contribute to the transmission of the virus (Chen et al. 2020). Few authors (Ma et al. 2020; Poole 2020; Sajadi et al. 2020 and Wang et al. 2020) have reported that climate indicators such as temperature and humidity influence the seasonal spread of corona viruses and even affect the mortality rate. Similar studies were reported by Shi et al. (2020), Liu et al. (2020), and Qi et al. (2020). Climate variability with extreme weather events induces respiratory disorders (Tatyana Vitkina et al. 2019). Few studies suggested that mortality due to respiratory diseases increased at low temperatures (GómezAcebo et al. 2013; Fallah and Mayvaneh 2016; Dadbakhsh et al. 2017). Cold and warm arid conditions may cause respiratory illness and have adverse impacts on mortality (Li et al. 2018). A study of temperature fluctuations in 30 East Asian cities reported respiratory and cardiovascular diseases with an impact of high mortality rates (Kim et al. 2017). In the cold season, the relative risk of respiratory, cardiovascular, and non-accidental deaths was observed to increase in Tabriz (Sharafkhani et al. 2019). Recent studies on COVID-19 in South Korea have estimated the decrease of daily new cases during the month of April 2020 (Petropoulos and Makridakis 2020). The persistence of the pathogens and their invasion threshold are the main factors to be understood for determining the geographical distribution and transmissibility of the disease (Deredec and Courchamp 2003). Some viruses may be more stable in environments with different climatic factors. In addition, people are more likely to stay indoors during winter, which leads to a decrease in vitamin D levels, thereby lowering immunity. Such conditions may stimulate the infection rate. Therefore, later studies confirmed that the impact of climatic factors on the spread of SARS-CoV-2 seems plausible (Chen et al. 2021).

A subgenera SARS-CoV-2 belongs to $\beta$-coronavirus (betaCoV), one among the four genera of ortho coronavirinae subfamily (Chan et al. 2013). The infection results in a respiratory disorder, leading to mortality of $10 \%$, and it is more sensitive to ultraviolet rays and temperature. When transcription regulatory sequences are located between open reading frames (ORFs), it leads to transcription termination and serves as templates for the development of subgenomic mRNAs. A minimum of 6 ORF can occur in a typical genome of CoV. The polypeptides pp $1 \mathrm{a}$ and pp $1 \mathrm{ab}$ are produced during the frame shift from ORF1a to ORF1b (Perlman and Netland 2009). Devoted sgRNAs translate the distinct accessory and structural proteins in various CoVs. The disease reversion and the potential pandemic nature depend on viral mutation (Cascella et al. 2020).

Two different types of lineage $\mathrm{L}$ and $\mathrm{S}$ were reported for the CoV-2 in Wuhan (Tang et al. 2020), and the former was more prevalent. Subsequent studies on the spike mutation (Korber et al. 2020) indicated that D614G was the predominant spike protein observed globally. Apart from this, L5F was also observed in 37 countries; Q239K, V483A, and D839Y/N/E in Europe; G476S and V483A in the USA; and P1263L in the UK. Though there are several spike proteins reported, D614G has resulted in the global pandemic, leading to a great impact on potential immunity due to its structure and mutation (Korber et al. 2020).

In view of all the above-reported studies and to have a comprehensive understanding of the transmission of the COVID-19, the present study has focused on the impact of meteorological parameters on COVID-19 of several affected countries from east to west around the world under different climatic conditions. The countries considered for the study were South Korea, China, Malaysia, Singapore, India, Kuwait, Italy, Spain, France, Germany, the United Kingdom (UK), and the United States of America (USA). Meteorological parameters (temperature, relative humidity, dew point, wind speed, and precipitation) of the selected countries were compared to the COVID-19 variables (total cases, daily new cases, active cases, total death, daily death (DD), and total recovery) to determine the influence of meteorological parameter toward the pandemic spread.

It also sought to understand if the influence of these parameters varied with climatic conditions. The current study was mainly concerned with the total number of infected cases rather than mortality as the mortality depends on the immunity of the population to the disease. The information on meteorological factors could help to strengthen the strategies of epidemiologists and health policy makers in combating and raising awareness of the COVID-19 pandemic.

\section{Methodology}

\section{Data collection}

The meteorological factors such as temperature, relative humidity, wind speed, dew point, and precipitation were considered for the present study (Fig. 1). The daily data 
Fig. 1 Methodology flowchart adopted in this proposed research

\section{SARS-CoV-2 phase I}

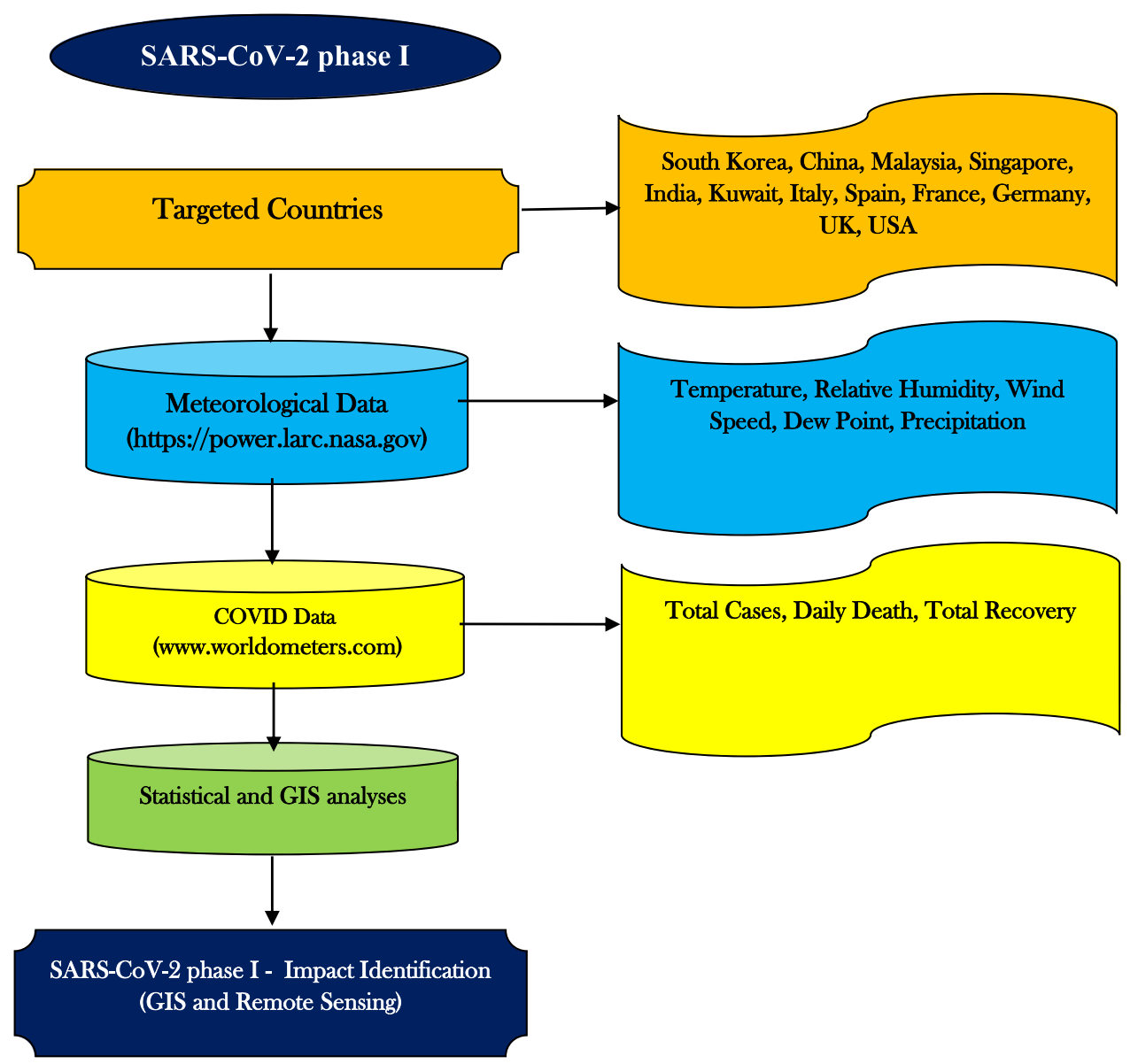

for the above-specified parameters were collected from the NASA website (https://power.larc.nasa.gov) for the period from $15 / 02 / 2020$ to $25 / 04 / 2020$ for all selected countries except for China (22/01/2020 to 25/04/2020), Malaysia, and Singapore (15/02/2020 to $19 / 04 / 2020)$. Since the data was available only for specific cities, an average of these daily parameters from different stations representing all directions of each country (geographically representing north, south, east, west, and central regions of the country) was considered for the daily meteorological condition of the country during the study period. The COVID-19 data was collected for the same period from www.worldometers.com for the respective dates of each country.

The following cities were selected for each country to have a geographic distribution in all directions: Busan, Seoul, Daejeon, Daegu, and Gwanju of South Korea; Wuhan, Shanghai, Guangzhou, Lanzhou, and Beijing station of China; Kuala Lumpur, Johour, Genting highland, Kuching, and Sabha from Malaysia; and Changi airport, Yishun, Jurong, Singapore city, and Choa Chu Kang of Singapore. Similarly, for India, the data was collected from Delhi, Ahmadabad, Nagpur, Mumbai, Kolkata, and Madurai stations. The data considered for Kuwait was from Salmiya, Jahara, Ahmadi, Mangaf, and Kuwait City. Italy includes the cities Turin, Milan, Vinice, Bari, Rome, Caglian, and Agrigento; Valencia, Bilbao, Salmanca, Sevilla, and Madrid were considered for Spain. Meteorological stations of Paris, Toulouse, Lyon, Bordeaux, Boulogne, Dijon, Brest, and Caen from France, and Berlin, Hamburg, Dortmund, Frankfurt, Baden, Munich, and Dresden from Germany were accounted for. London, Belfast, Edinburgh, Norwich, Bristol, and Birmingham were the selected cities of the UK, and finally, the USA was represented by San Francisco, New York, Minnesota, Texas, Florida (Orlando), Kansas, and Washington (Spokane). The following discussion considered South Korea, China, Singapore, Malaysia, India, and Kuwait as Asian countries, whereas Italy, Spain, Germany, France, the UK, and the USA were considered as western countries.

\section{Data analysis}

Correlation and factor analyses were performed for the meteorological parameters and COVID-19 data from the initiation of lockdown of each country until 25/04/2020. Pearson correlation was adopted for the COVID-19 parameters and meteorological parameters of each country, where values above $0.50-0.75$ were considered as good correlation and values above $0.75-1.00$ were considered as excellent 
correlation (Vasanthavigar et al. 2013). Principal component analysis was also performed on the selected data to determine the factors representing COVID-19 variables and meteorological parameters. Varimax rotation and Kaiser normalization were used to extract eigenvalues greater than one (Thivya et al. 2015). The data source for the mutation study was acquired from GISAID based on recent data and can be accessed at www.cov.lanl.gov.

\section{Results}

The pandemic initiated in these countries during different time periods, and the impact varies with respect to the counties. The variations of the pandemic nature in each country were discussed as follows.

\section{South Korea}

The data pattern indicates an exponential rise of overall cases; mortality and recovery rates increased after $04 / 03 / 2020$. Total new cases were higher on $15 / 02 / 2020$, although the first case was reported on 19/01/2020 (Supplementary Fig. S1). More new cases were reported during the end of February and subsequently reduced since then. The rate of recovery has significantly increased from the first week of February. The death case fluctuated with no definite trend. In comparison with meteorological parameters, there is an increase in temperature observed during this study period and a gentle decrease in humidity (Supplementary Fig. S2). The peak of daily death cases matches with the decrease in humidity from the first week of March to the first week of April. A higher amount of precipitation is observed during the study period than in any other country. The wind did not play any significant role in the COVID-19 spread. The daily death cases and the pandemic spread are dependent on meteorological parameters, especially temperature and humidity (Ma et al. 2020).

The correlation analysis of the data with COVID-19 and meteorological variables shows that temperature has a good correlation to total infected cases, active cases, total death, and total recovery and negative correlation with daily new cases (Supplementary Table S1). Furthermore, humidity also showed a good correlation with total cases. The results indicate that the effect of temperature and humidity play an important role in COVID-19 cases in South Korea. A positive correlation was also noted between humidity, dew, and precipitation. Humidity also correlated with decreased lung function and increased exacerbations for COVID-19-affected patients (Donaldson et al. 2001). The PCA analysis (Supplementary Table S2) shows a representation of 5 components from the data set, of which the first component is represented by all COVID-19 variables and temperature along with dew point. There are no significant representations of COVID-19 variables with other components (Qasim et al. 2020).

\section{China}

The temperature and dew point show a similar variation trend. The lockdown was initiated in Wuhan on 26/01/2020. The daily death cases increased slowly from 23/01/2020 to $23 / 02 / 2020$ and gradually decreased (Supplementary Fig. S1). The meteorological parameters show that there is an increase in temperature and dew point during the study period. Adversely, there was a moderate decrease in the humidity during the study period. The increase in mortality was observed since the first case was reported. The daily death cases reduced after 10/02/2020, during which a drop in temperature (Supplementary Fig. S2) and an increase in precipitation were observed. Hence, it is inferred that precipitation plays a major role in controlling death cases.

A significant correlation existed between temperature and total death, total cases, and total recovery (Supplementary Table S1). Similarly, a good correlation between dew point and total death, total cases, total recovery, and temperature was observed. In China, three factors were extracted from the data set based on eigenvalues. The first factor mainly contributed by total death, total cases, total recovery, dew point, and temperature (Supplementary Table S2). The results reveal that temperature plays a significant role in pandemic spread (WHO, 2019). Other factors were not related to the COVID-19 spread.

\section{Malaysia}

The first case of COVID-19 was recorded on 25/01/2020 in Malaysia, and four different trends were observed with respect to the total cases. A steep increase was observed in daily new cases until 17/03/2020 with minor fluctuation. It was clearly depicted that the daily new cases were stabilized from the lockdown period 18/03/2020 to 14/04/2020, and subsequently, a drop in the infected cases was observed. After 17/03/2020, the number of daily death cases was fluctuating, and the maximum number of daily deaths was observed on 29/03/2020. There was a sharp increasing trend of total recovery cases from $15 / 02 / 2020$ to $20 / 04 / 2020$. The number of recovery cases was stable, and a sudden increase in recovery was noted after 10/03/2020.

Supplementary Fig. S1 shows that the number of daily deaths had a similar trend with respect to temperature before and after the lockdown period. Prior to the lockdown period, the temperature was around $78^{\circ} \mathrm{F}$, where there was no record of death. After the lockdown period, the temperature increased to around $80^{\circ} \mathrm{F}$. Temperature changes may add to the strain of the cardiac and respiratory systems that cause cardiopulmonary events (Sharafkhani et al. 2019). So, 
it was clear that the temperature is an important factor for COVID-19 mortality in the country. Dew point data also followed the same trend of temperature (Supplementary Fig. S2). The amount of precipitation fluctuated throughout the study period. Particularly, low precipitation was recorded when the daily death rate was higher. Humidity is also an important factor for respiratory diseases (Davis et al. 2016a, 2016 b). Before the lockdown period, the humidity values fluctuated around $88 \%$, and after the lockdown period, the value decreased to $80 \%$. Thus, lower humidity correlates with a high mortality rate. A few researchers have also confirmed that low humidity can increase respiratory infections (Barreca 2012; Barreca and Shimshack 2012). Wind speed values decreased after the closure period, but there was no indication of clear positive relation to COVID-19 deaths.

The correlation coefficients between COVID-19 variables and meteorological parameters show that temperature was positively correlated with total cases, active cases, total deaths, and total recovery (Supplementary Table S1). Hence, the temperature is one of the main meteorological factors governing the pandemic spread in Malaysia. Humidity was negatively correlated with total cases, active cases, total deaths, and total recovery. The correlation output reveals that lesser humidity favors COVID-19 mortality cases after the lockdown period. Principal component analysis shows that a total of 3 factors were extracted based on eigenvalues (Supplementary Table S2). Factor 1 shows positive loadings of total cases, active cases, total deaths, daily deaths, total recovery, and temperature. It is clearly indicated that temperature controls most of the COVID-19 variables (Chen et al. 2020). Humidity was negatively loaded with COVID19 variables, which shows humidity also plays an important role in COVID-19 spread. There was no significant representation of the loadings in factors 2 and 3.

\section{Singapore}

The first case of COVID-19 was recorded on 23/01/2020 in Singapore. A total of 3 trends were observed from the total cases from 15 to 28 February 2020; the total cases were slowly increasing within the range of 72 to 98 (Supplementary Fig. S1); subsequently, there was a gradual increase (the second trend) observed from $29 / 02 / 2020$ to $31 / 03 / 2020$, and the values were ranging from 102 to 926 , and later, there was an increase observed from 1000 to 6588 total cases during the period from $01 / 04 / 2020$ to $19 / 4 / 2020$. The public movement was restricted from 07/04/2020. There was a sharp increase in the number of infected cases from 06/03/2020, and the numbers gradually increased until 18/04/2020. It is interesting to note that the numbers increased exponentially after the lockdown period. There was a sharp increasing trend of total recovery cases from $15 / 02 / 2020$ to $21 / 02 / 2020$, and the number gradually increased until 19/04/2020. It is observed that the recovery numbers have not significantly increased after the lockdown period.

The temporal changes of COVID-19 daily mortality cases and the meteorological factors such as temperature, relative humidity, wind speed, dew point, and precipitation were studied. The number of daily mortality increased from 02/04/2020 (Supplementary Fig. S2). The temperature was stable around $81^{\circ} \mathrm{F}$ from $15 / 02 / 2020$ to $30 / 03 / 2020$ (before lockdown period), and a sharp increasing trend of $85^{\circ} \mathrm{F}$ was observed during the period with high mortality. It indicates that the increase in temperature matches with the mortality rate. The changes in temperature can enhance respiratory problems (Sharafkhani et al. 2019). Dew point data also follow the same trend of temperature. It was clearly observed that there was a decrease in humidity during the mortality period, which shows that low humidity matches with the daily death cases (Barreca and Shimshack 2012), stimulating respiration diseases. It is also interesting to observe that the high precipitation and wind speed values correlated with the daily death periods. Overall, the wind speed shows a declining trend from February to April, particularly a significant drop during COVID-19 mortality periods.

The correlation between COVID-19 cases and meteorological parameters shows that temperature has a positive correlation with total cases, daily new cases, active cases, total deaths, and total recovery (Supplementary Table S1). Similarly, wind speed has a good correlation with total cases, daily new cases, active cases, total deaths, and total recovery. Humidity and precipitation show a negative correlation with all the COVID-19 variables except daily deaths. So, temperature and humidity are the main meteorological factors considered to increase the total cases. There is a lesser influence on precipitation and wind speed. A total of 3 factors were extracted by PCA analysis (Supplementary Table S2); factor 1 is positively loaded with total cases, daily new cases, active cases, total deaths, total recovery, temperature, and wind speed (Wu et al. 2020). Hence, it is conclusive that temperature and wind speed control the total COVID-19 cases. Factors 2 and 3 do not show any significant loading with most of the variables.

\section{India}

An increase of temperature from $80^{\circ} \mathrm{F}$ to a maximum of about $100^{\circ} \mathrm{F}$ during the study period was observed. There has been a decrease in humidity observed during this period, especially after the lockdown (24/03/2020). The period of decrease in humidity shows an increasing pattern of daily death cases due to COVID-19 (Supplementary Fig. S1). The increase of precipitation peaks is observed during the drop in daily death cases. Cases of COVID-19 in India were reported at the end of January 2020 (Bagyaraj et al. 2020). The acceleration began after the first 
week of March 2020. There was a steady rate of increase in total affected cases and those recovered since the second week of March 2020. The mortality rate exponentially increased after 30/03/2020.

In India, a significant correlation existed between temperature and total cases, daily new cases, active cases, total death, daily death, and total recovery. Temperature influences the pandemic spread and mortality rate (Supplementary Fig. S2). Abrupt changes in temperature can add to the strain of the cardiac and respiratory system triggering cardiopulmonary events, as rapid variability in daily temperature can contribute to environmental stress (Easterling et al. 1997, Sharafkhani et al. 2019). Good correlation exhibits between precipitation and dew point; humidity with dew point and precipitation (Supplementary Table S1). A negative correlation was observed between humidity and daily new cases, temperature, along with daily death. The PCA analysis extracts two major components, of which the first component was represented by the COVID-19 variable along with temperature and moderate positive loadings of dew point (Supplementary Table S2). Moderate negative loading of humidity in the first component (Ma et al. 2020) was also observed. The second component does not represent the COVID-19 variables.

\section{Kuwait}

Kuwait showed a substantial increase in total cases after $05 / 04 / 2020$ and death cases after $14 / 04 / 2020$. There is an increase in the temperature from 60 to $85^{\circ} \mathrm{F}$ during the study period (01/02/2020 to 25/04/2020) (Supplementary Fig. S1). The fluctuation of humidity has influenced temperature. Though there is no significant amount of precipitation in the country, a $4.5 \mathrm{~mm}$ of rain event was observed on 15/04/2020, followed by an increase in the amount of mortality and the number of people infected (Supplementary Fig. S2). But still, there has been a period of increase in temperature and lesser humidity from 13/03/2020 to 15/04/2020 which might have favored the pandemic spread after 15/04/2020.

The correlation analysis of the meteorological parameters to the COVID19 variables reflects that the temperature has a good correlation with total cases, daily new cases, active cases, and even total recovery (Supplementary Table S1). A poor negative relationship of wind and humidity was noted with the COVID-19 variables. The rotated component matrix with these variables extracted three factors, and the significant first-factor loadings were represented by temperature (the only meteorological parameter) associated with the pandemic propagation (Supplementary Table S2). It can be inferred that temperature variations in Kuwait influenced the spread during the study period in association with less humidity and rainfall events (Baumgartner et al. 2012).

\section{Italy}

Initial observation in Italy shows that there has been a lapse time of 38 days since the initial case and the lockdown period. There was a steep increase in the total number of new cases and mortality till 27/03/2020. Subsequently, the slope became gentle and decreased further from 29/03/2020. There has been an exponential increase in the total recovery after 21/03/2020 (Supplementary Fig. S1). The temperature was observed to be around $50^{\circ} \mathrm{F}$ from $15 / 02 / 2020$ to $10 / 03 / 2020$; since then, there has been a sudden fluctuation in temperature observed which finally rose after 05/04/2020. The maximum temperature observed during the study period was noted at the end of April 2020. Respiratory disorders are less common during the warmer period (Zhang et al. 2014). The persistence of extreme acute respiratory syndrome coronavirus (SARS-COV) was a reflection of temperature and humidity variation in the atmosphere (Lisa et al. 2010). The duration from 09/03/2020 to 05/04/2020 showed a drastic increase in mortality and total infected case (Supplementary Fig. S2). The daily mortality matched perfectly with the variation in humidity and fluctuation in temperature. It was noted that prior to the increase in death rate, there has been an increase in wind speed and precipitation. Hence, this trend reveals the influence of meteorological parameters in COVID-19 spread.

The dew point factor also has a correlation to the total recovery; humidity shows a negative correlation to COVID19 variables. It is also inferred that the temperature and the wind speed have a negative relationship (Supplementary Table S1). Thus the increase of wind speed decreases the temperature which in turn influences the COVID-19 variable (Oliveiros et al. 2020). The rotated components of the factor analysis (Supplementary Table S2) has extracted four factors, and it shows that the first factor is loaded with temperature and total case, active case, total death, and total recovery, similar to other countries which inferred that the humidity and wind speed as a negative representation to the COVID-19 variables.

\section{Spain}

The COVID-19 outbreak may be affected by several parameters, including social and political factors, geographic factors, and climate factors (Wu et al. 2020). The temperature and dew point show a similar trend. Likewise, the trend of the precipitation and wind speed shows similar observations. The temperature, humidity, precipitation, wind speed, and dew point of meteorological parameters may cause environmental stability or affect the viability of viruses. A fluctuation in humidity, temperature, dew point, and precipitation was observed during the study period. The highest humidity (88.92) was recorded on 31/03/2020 (Supplementary 
Fig. S1). There was a steady increase in the total death cases from 14/02/2020 to 01/04/2020; subsequently, there was a drop in daily death cases due to COVID-19. In general, the peak of death cases was observed during the period of lesser temperature and higher humidity. It is also observed that there is a slight decrease in death cases, followed by precipitation events after 20/03/2020. Temperatures were also observed to have an impact on pandemic transmission (Supplementary Fig. S2). In particular, the variations in temperature and humidity are important factors affecting COVID-19 mortality (Ma et al. 2020).

Temperature shows a significant correlation with total recovery, total death, and total cases. A good correlation was observed between temperature, dew point, total death, and total cases (Supplementary Table S1). Three factors were extracted by PCA analysis. Factor 1 was loaded with COVID-19 variables, temperature, total recovery, total death, total cases, and dew point (Supplementary Table S2). Factor 2 was represented by daily death and daily new cases with a negative relation to temperature and dew point.

\section{France}

There were very few cases reported till the end of February. An increasing trend was observed gradually, and the number of new cases started to increase to thousands by $16 / 03 / 2020$. Although the number of cases was increasing, the recovery was not significant until 16/03/2020. Then, the lockdown was functional from 17/03/2020 with a coincidence of recovery cases. It was observed that from $11 / 04 / 2020$ to $21 / 04 / 2020$, the daily new cases reported were stable, and further reduction has been observed after 21/04/2020 (Supplementary Fig. S1). The highest number of deaths was observed on 15/04/2020, with the total count as 1438 , and then the decreasing trend continued. To understand the cause for the rise in the number of cases and reduction, a correlation was made with the environmental factors such as temperature, dew point, precipitation, humidity, and wind speed with respect to the daily new cases and deaths (Supplementary Fig. S2). It was noticed that from 04/04/2020, higher temperatures were observed; concurrently, the number of positive cases dropped from 17,355 to 6559 and slowly stabilized. The influence of temperature played a vital role in the decrease in the number of news cases observed, and the death rate has gradually dropped. Higher humidity was evident to influence the pandemic spread. The ideal humidity should be around 40-60\%, as respiratory disorders are minimized at 40-60\% humidity (Anthony et al. 1986). Initially, during the study period, the humidity was high even though there were not many cases. But when the cases increased, it was observed that the highest number of cases was recorded at 17,355 as the humidity was $70 \%$. Subsequently, as the humidity started decreasing, the number of cases also decreased.

A good correlation was observed between the temperature and the active cases as well as total cases (Supplementary Table S1). A similar observation was identified with the deaths and recovered cases. Hence, higher temperatures would reduce the spread of COVID-19 and have more chances for recovery. Since the dew point, precipitation, and humidity have a good correlation, these three factors which are interrelated would definitely play a role in the pandemic spread (Ficetola and Rubolini 2020). The rotated component matrix (Supplementary Table S2) of the whole data indicates that temperature, dew point, and precipitation along with COVID-19 variables are represented in the first component except daily new cases. The second component signifies dew point, humidity, and precipitation, reflecting a negative influence on mortality and new cases.

\section{Germany}

Germany recorded the first case of COVID-19 on 27/01/2020. The actual rise in the cases started from March and increased exponentially by 22/03/2020 (Supplementary Fig. S1). Although the lockdown was functional from $23 / 03 / 2020$, the number was higher due to other environmental factors. There was no influence of precipitation on the COVID-19 cases in Germany. Temperature and dew point have a relation with the number of total cases. An increase in temperature has decreased the number of new cases. Dew point is one of the most important factors that has influenced the COVID spread in Germany. Low dew point at a particular period (22/03/2020 to 02/04/2020) was identified as the number of cases has increased and also showed a good correlation in the statistical analysis. As the dew point increased slowly, the gradual decrease was observed from 03/04/2020 (Supplementary Fig. S2). Subsequently, it was observed that low temperatures were also recorded during the same period which could have accelerated the spread of COVID-19 and increased the number of cases. The total number of cases decreased with the increase in dew point, and the number of recovered cases increased with higher dew point. The daily death cases decreased during the increase in temperature and dew point, especially from 15th March. The humidity did not play any role although observed higher during initial days, but there is a decrease in humidity from 15/03/2020 to $10 / 04 / 2020$, which coincided with the peak of daily deaths in the country.

There was a positive correlation between temperature, dew point, death cases, and total cases (Supplementary Table S1). Dew point correlated with most of the COVID19 variables in the country. Humidity has a moderate positive correlation to total cases, and wind speed has a negative correlation to the total cases (Ji et al. 2020). The rotated 
component matrix of the data reveals the loadings of temperature and dew point along with COVID-19 variables in the first component (Supplementary Table S2). The second component was loaded with dew point and humidity with a negative representation of wind speed, reflecting their influence on daily death cases. It is thus inferred that the first component influences the total cases or the transmissibility of the pandemic and the second reflects the influence on death cases.

\section{United Kingdom}

The number of COVID-19 cases increased at a constant rate until the end of February and then began to spread exponentially. Daily new cases have increased drastically from the end of February. Daily mortality also progressively increased from 13 March to 25 April 2020 (Supplementary Fig. S1). Total cases recovered were constant during the months of March and April (135 to 344), and no significant number of recovered cases were reported until the end of the study period. On 20 March 2020, the government announced the lockdown across the country to prevent the further spread of the COVID-19 pandemic. Meteorological factors can play a vital role in daily deaths. The pattern of total death cases from 28th February onwards perfectly matches with the fluctuation trend of humidity. Humidity has been a significant factor in influencing the daily deaths from the end of February to April. Though there was a drop in humidity after the lockdown, there has been a fluctuation in the average values corresponding to the variation in temperature and precipitation (Supplementary Fig. S2). The rapid increase in temperature and dew point in April 2020 has randomly increased the number of death cases. It is also observed that few periods with higher wind speed has resulted in the decrease of daily death cases.

There was a good correlation between temperature, active cases, and daily deaths (Supplementary Table S1). Similarly, a good correlation was found between dew point and daily deaths, active cases, and total deaths (Wang et al. 2020). Although three factors were extracted from the current data, the first factor was represented by temperature and all COVID-19 variables, reflecting the influence of temperature on the spread of the pandemic (Supplementary Table S2). The second factor had the negative representation of wind speed and positive loadings of dew and temperature, which resulted in an increase or decrease of daily new cases and daily deaths.

\section{United States of America}

The instances of COVID-19 were reported in the USA from the last week of January. However, the number of COVID-19 cases had increased at a constant rate until the end of February, and subsequently, it exploded exponentially (Supplementary Fig. S1). Daily new cases, daily death, and recovery rates also increased gradually from the first week of March (04 March to 14 April). The meteorological factors may have a vital role in daily deaths (Supplementary Fig. S2). The gradual increase in temperature and precipitation in April 2020 has randomly augmented the number of death cases. Low humidity is also an environmental impact of the COVID-19 outbreak. At the same time, it can be perceived that other factors like dew point showed no impact on daily death. The increase in wind speed shows a negative trend in daily death, and the daily death cases were observed to be reduced after a few significant rain events during April $13,15,22$, and 25.

A good correlation was observed between temperature with total recovered cases, and humidity showed a negative correlation with total cases, active cases, and daily deaths (Supplementary Table S1). A moderate correlation was observed between the total cases, daily cases, active cases, and total and daily deaths and the humidity with total deaths and recovered cases. The rotated component matrix of the PCA shows the positive loadings of temperature and all COVID-19 variables with negative loading of humidity (Supplementary Table. S2). The lung function generally in a colder environment differs from that of the warmer environment (Joseph et al. 2018) which could have been a governing factor for the distribution of COVID-19 in colder regions. The second component is represented by the positive loading of dew, temperature, and humidity with negative loading of wind speed, reflecting a weak relation to daily death.

\section{Discussion}

The details of lockdown periods implemented in respective countries, population density, total COVID-19 cases, and the maximum, minimum, and average of the meteorological parameters are depicted in Table 1. Significant influence of population density (PD) was not observed with mortality in Wales, England (Chowell et al. 2010), and New Zealand (Haidari et al. 2007) during the spread of the 1918 Influenza pandemic. But studies by Linder and Grove (1947) on the mortality with respect to 1940 pneumonia spread in the USA shows a good correlation with population density. The discussion with respect to population density was not appropriate when there is a non-uniform distribution of population. Since the fear of spread is generally governed by the population density, an attempt has also been made to know the influence of the population density on the pandemic. Among the countries considered for the study, the highest population density (http://creativecommons.org/ licenses/by/3.0/igo/) was observed in Singapore (8357.6), followed by South Korea (527.3) and India (464.1), and 


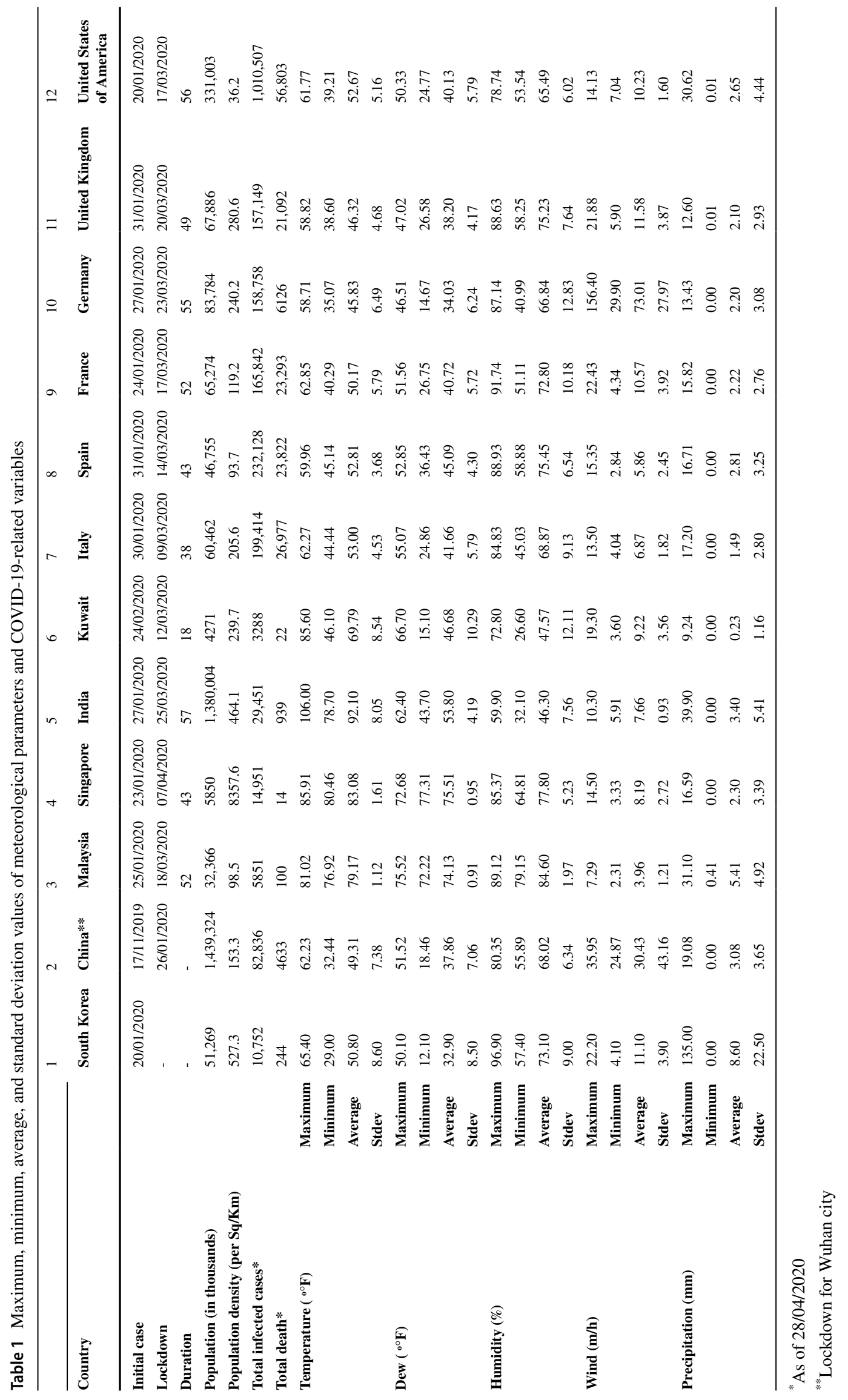


the lowest is USA (36.2). The pandemic affected more in the USA, followed by Spain, Italy, and France, exhibiting regions with lesser population density. The spread was noted in China from November 2019 and in other countries in February 2020. Hence, the period of study in China was from $17 / 11 / 2019$ to $1 / 2 / 2020$ and for other countries from $1 / 2 / 2020$ to $25 / 4 / 2020$. There were two definite trends observed with respect to the population density: one with a positive trend in the countries Malaysia, Kuwait, South Korea, India, and Singapore (increases the infection rate with increase in population density) and a negative trend in the countries Italy, Germany, Spain, France, the UK, and the USA. The approaches relating to pandemic or epidemic disease with respect to population density have still been inconclusive due to the variation in the spatial interval of $\mathrm{PD}$ and the immunity of the population. Mathematical models have been adopted to determine the threshold considering the assumptions (Hu et al. 2013, Kumberger et al. 2016), but the current study reveals that the PD also has an influence on the pandemic. Although a negative trend with respect to the USA, the UK, and the European countries was considered, it should be understood that the downscaling of PD with respect to specific pandemic cities of the country will reflect a more precise scenario (Fig. 2). The distribution of $\mathrm{PD}$ is the most important factor in dispersal. The relationship between PD and pandemic spread (total number of cases) shows a different trend in the Asian countries studied $(\mathrm{Hu}$ et al. 2013).

The pandemic has led to focus on several dimensions: The time period between the initial case identified and the implementation of movement restriction (lockdown) plays another significant role (Table 2). The detection and prevention of the pandemic at the initial stages would avoid the Allee effect. The time-lapse between the first reported case in the country and the movement-restricted period (lockdown) also governs the transmissibility of COVID-19. The Asian countries show that (Fig. 2) there is a direct relationship between these two factors. Although the time-lapse in the countries of Europe, the UK, and the USA are similar to that of the Asian countries, they do not show a direct relationship, thus revealing the influence of additional factors in the pandemic spread in these regions (Gupta et al. 2020).

The average temperature of each country during the pandemic period shows a clear demarcation between the Asian countries and the countries of Europe, the USA, and the UK, except for China and South Korea (Fig. 2). The distribution shows two different clusters: one with lower and other with higher temperature regions; but it is interesting to note that the increase of temperature has resulted in the increase of spread. The influence of COVID-19 in humid and warmer
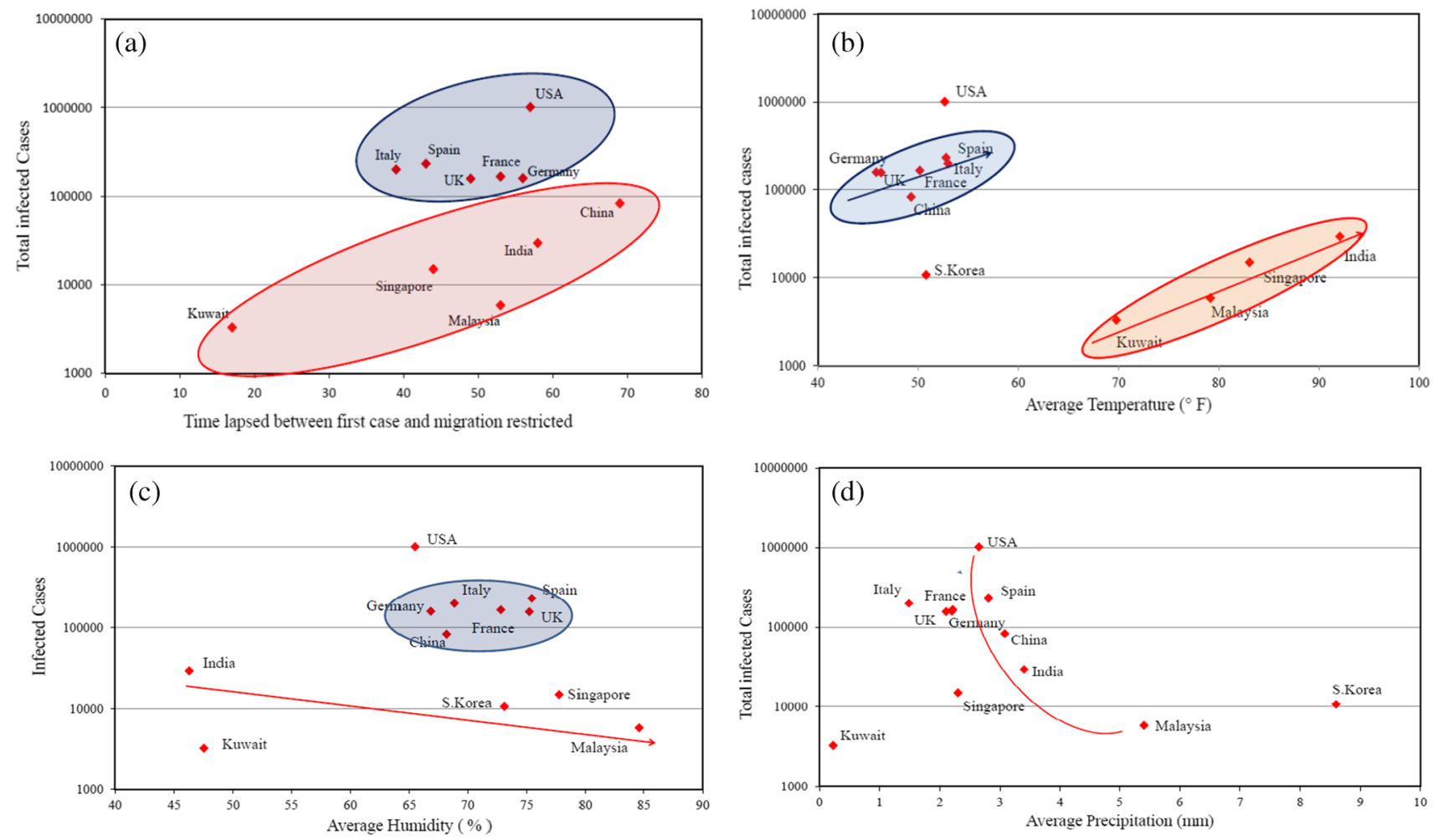

Fig. 2 Impact of time-lapsed period (a), average temperature (b), average humidity (c), and average precipitation (d) to the total infected cases in different countries 


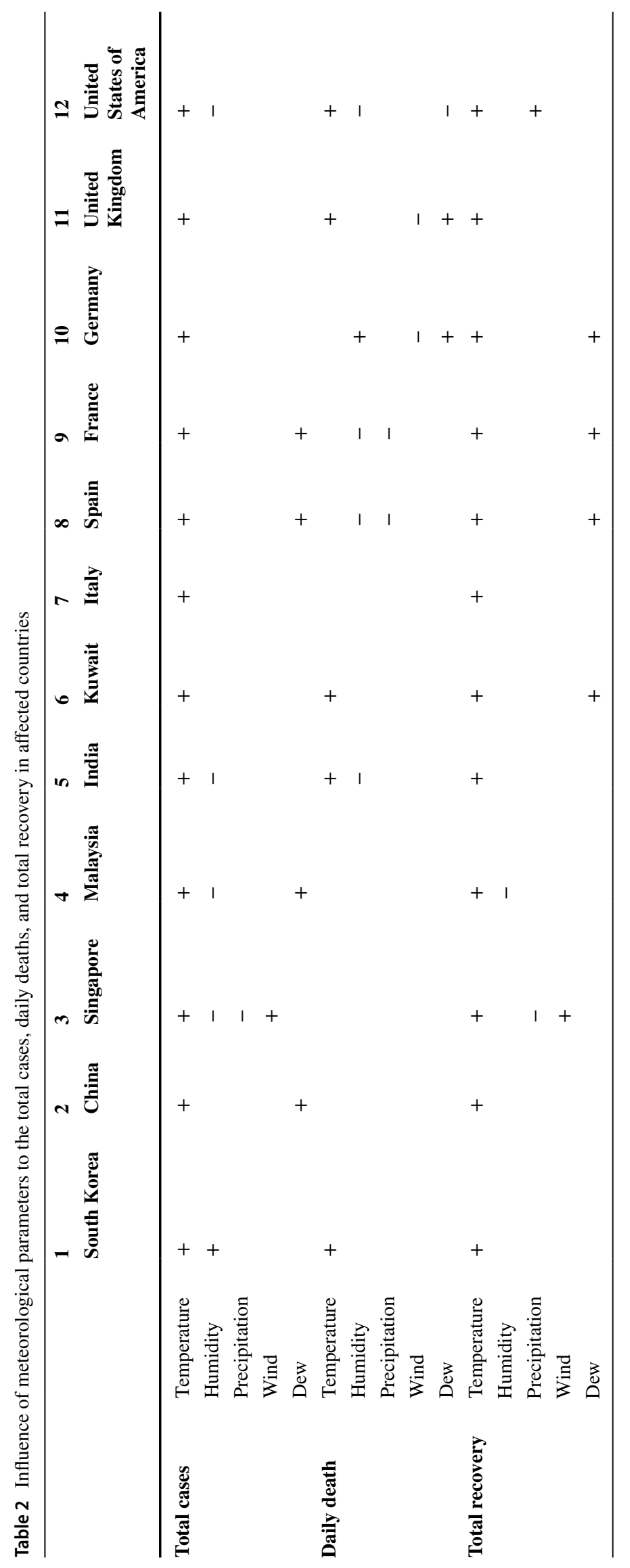


conditions was reported to spread at a lower rate though it depends on other parameters like population density and social distancing. The viral respiratory outbreak is more common in cooler climates (Chew et al. 1998). The fine droplets of submicron 100-1000 nm sizes and contagious aerosols have also resulted in the spread of respiratory disorder (Lindsley et al. 2013; Yan et al. 2020; Hicks et al. 2018).

Similar to temperature, average humidity values also show a negative trend. An increase in humidity decreases the spread of infection in Asian countries; although humidity is higher in Europe, the UK, and the USA, there is no significant effect of this parameter (Fig. 2). Variation in humidity leads to the spread of COVID-19 (Liu et al. 2020), as respiratory illnesses generally increase during winter and cold climatic conditions (Shaman and Kohn 2009, Shaman et al. 2011). The previous studies on COVID-19 show that transmission is favored by low humidity and low temperatures, which could change with higher air temperatures (Liu et al. 2020). Average precipitation shows a negative influence on the transmissibility of the pandemic, as a higher amount of precipitation was observed in South Korea and Malaysia relatively than other countries during the study period (Fig. 2). Kuwait is an arid region and shows lesser precipitation during this period, and it is a time of transition from cooler to warmer summer (Liu et al. 2020). The countries of Europe, the UK, and the USA reflect higher pandemic spread with lesser precipitation. The increase in the amount of precipitation decreases the spread of respiratory disorder (de Souza et al 2012). Modeling of the climatic factors on the transmissibility and mortality of COVID-19 reflects that it is inversely related to temperature to the total cases and precipitation as a significant factor (Sobral et al. 2020).

The major concern about the COVID-19 spread is the total infected, daily death, and total recovery, as the other factors like total active cases and total deaths are interdependent on these factors. An inference was derived from the study relating the meteorological parameters to these three COVID-19 variables with respect to the selected countries. There are still regions with specific variations influencing the spread by lesser humidity in Singapore, Malaysia, India, and the USA, but increase with humidity in Korea. The propagation of the COVID-19 spread is faster when compared to the normal seasonal flu. Earlier SAR-COV proved that temperature and humidity are the basic factors to determine the persistence of the virus. It is also observed that an increase in wind speed and decrease of precipitation in Singapore promote the pandemic spread. An increase in dew point in general increases the spread in China, India, Spain, and France.

The daily morality was governed by the temperature in South Korea and Kuwait. In India, it was governed by a decrease in humidity and an increase in temperature. Spain and France showed that the daily death case was governed by a decrease in humidity and precipitation. In Germany, an increase in humidity and dew point along with a decrease in wind speed controlled the daily morality. An increase in temperature and dew point along with a decrease in wind speed governs the daily death in the UK. The mortality trend in the USA shows that the decrease of dew point and humidity along with the increase of temperature governs morality. No definite relation could be generalized for China, Singapore, Malaysia, and Italy with respect to daily morality (Liu et al. 2020).

The total recovery was reflected to be increased at high temperatures, irrespective of the geographical location. The recovery was also facilitated by the increase of dew points in Kuwait, Spain, France, and Germany. The decrease of precipitation and increase of wind speed apart from temperature has added to the recovery rate in Singapore. It is also observed that the decrease in humidity and the increase in precipitation facilitate the total recovery in Malaysia and the USA, respectively, along with an increase in temperature.

The matrix of meteorological parameters to COVID-19 variables shows that temperature and humidity are the major variables governing the pandemic spread. It was inferred that the earlier SARS-COV virus existed in a temperature ranging from 71.6 to $77^{\circ} \mathrm{F}$ and a humidity condition ranging from 40 to $50 \%$. Studies reported that the virus could not sustain with temperatures greater than $95^{\circ} \mathrm{F}$ and humidity above $95 \%$ (Chan et al. 2013). The trend of average temperature and humidity for the countries measured during the study period shows that the greater influence was observed in countries falling between 65 and $75 \%$ humidity and $45-55^{\circ} \mathrm{F}$, especially in countries with $51-53^{\circ} \mathrm{F}$ (Fig. 2). But, South Korea was reported to be less affected by the pandemic and observed to fall in this region. Therefore, a crossplot between temperature and precipitation showed (Supplementary Fig. S3) that South Korea had a higher amount of precipitation than the other countries with temperatures less than $55^{\circ} \mathrm{F}$. Hence, there is a clear demarcation that temperature greater than $65^{\circ} \mathrm{F}$ and precipitation above $5 \mathrm{~mm}$ would have a negative impact on the COVID-19 spread (Mecenas et al. 2020). Significant variation with respect to temperature, humidity, and precipitation was observed between the Asian and western countries.

The study also extended the variation in the spatial distribution of temperature and humidity with respect to the countries considered in this study. In this regard, temperature and precipitation data were collected for 140 locations evenly distributed throughout the world (https:// power.larc.nasa.gov), and data were extracted for the following dates: 15/02/2020, 15/03/2020, 15/04/2020, and 25/04/2020. The data collected for these regions were spatially plotted in the world map for four different time periods. The spatial distribution maps of these time periods for 
temperature and humidity was compared to the pandemic spread in the countries through time series (TS) analysis.

There is an increased number of cases during the study period (15/02/2020 to 25/04/2020). The time series observation on spatial temperature distribution reflects that the northern hemisphere had a temperature of $<51-69^{\circ} \mathrm{F}$ on 15 March 2020 which migrated northwards till 25 April 2020 (Fig. 3). After 25 April 2020, most of the European countries were represented by temperature $>69^{\circ} \mathrm{F}$, but few hotspots with temperature $<51^{\circ} \mathrm{F}$ were still observed in northern Europe, England, the USA, and Russia. While the equatorial regions experienced temperature $>69^{\circ} \mathrm{F}$ during March, and it further increased during April. Studies have reported survival of COVID-19 on surfaces materials for a period ranging from 5 to 28 days (Kampf et al. 2020) in temperature around $68^{\circ} \mathrm{F}$ and proved that ora/naso pharyngeal portions are most affected when the temperature was above $60^{\circ} \mathrm{F}$ (Grasmeijer et al. 2015) especially at higher humid conditions (Golshahi et al. 2014). Most of the southern hemisphere and the equatorial region had a humidity $<65 \%$ during 15 March 2020 . The humidity hotspots $>85 \%$ were observed in northern Europe, China, and the USA. This hotspot intensified during the subsequent periods (15 March and 15 April 2020), followed by a reduction in humidity after 25 th April 2020. It should be noted that few hotspots persisted around the USA, Malaysia, and Singapore and that there was a decrease in the spatial representation of lesser humidity values near the equatorial region, which favored the pandemic spread in these regions (Fig. 4).
All the European countries considered for the study along with the USA and the UK fall within $60^{\circ} \mathrm{F}$ with greater humidity during the period of study could be an important driving force for the pandemic spread. An increase in temperature pattern and the reduction of humidity would help in curtailing the pandemic spread. The impact of an increase in optimum humidity $>65 \%$ was observed in Asian countries on 25 April 2020, which could enhance the pandemic spread in these regions apart from social distancing. The transmittance of the virus is also facilitated by the wind pattern prevailing in the region, as it shows a positive relationship in Singapore.

The studies revealed the humidity and temperature effects on respiratory disorders (Sarangapani and Wexler 1996; Xi et al. 2015; Alexander 2019). The situation becomes more complex when the indoor temperature is maintained at a variation greater than $5^{\circ} \mathrm{C}$ than the external environment (D`Amato et al. 2018: Vitkina et al. 2019). The regions with higher humidity and lower temperature play an important role in the spread of the pandemic. There is an increase of total cases with respect to time, and the regions with higher cases were favored by temperature and humidity. Furthermore, the meteorological variables control the density of air and the distribution of $\mathrm{O}_{2}$ and $\mathrm{CO}_{2}$ in the atmosphere (Bu et al. 2020). The temperature and humidity control the variation of $\mathrm{CO}_{2}$ and $\mathrm{O}_{2}$ in the atmosphere. During summer, biologically, more $\mathrm{O}_{2}$ is evolved and it is favored by higher temperature and lesser solubility. The abiotic and biotic variable of seasonality variation promotes $\mathrm{O}_{2}$ in the atmosphere during

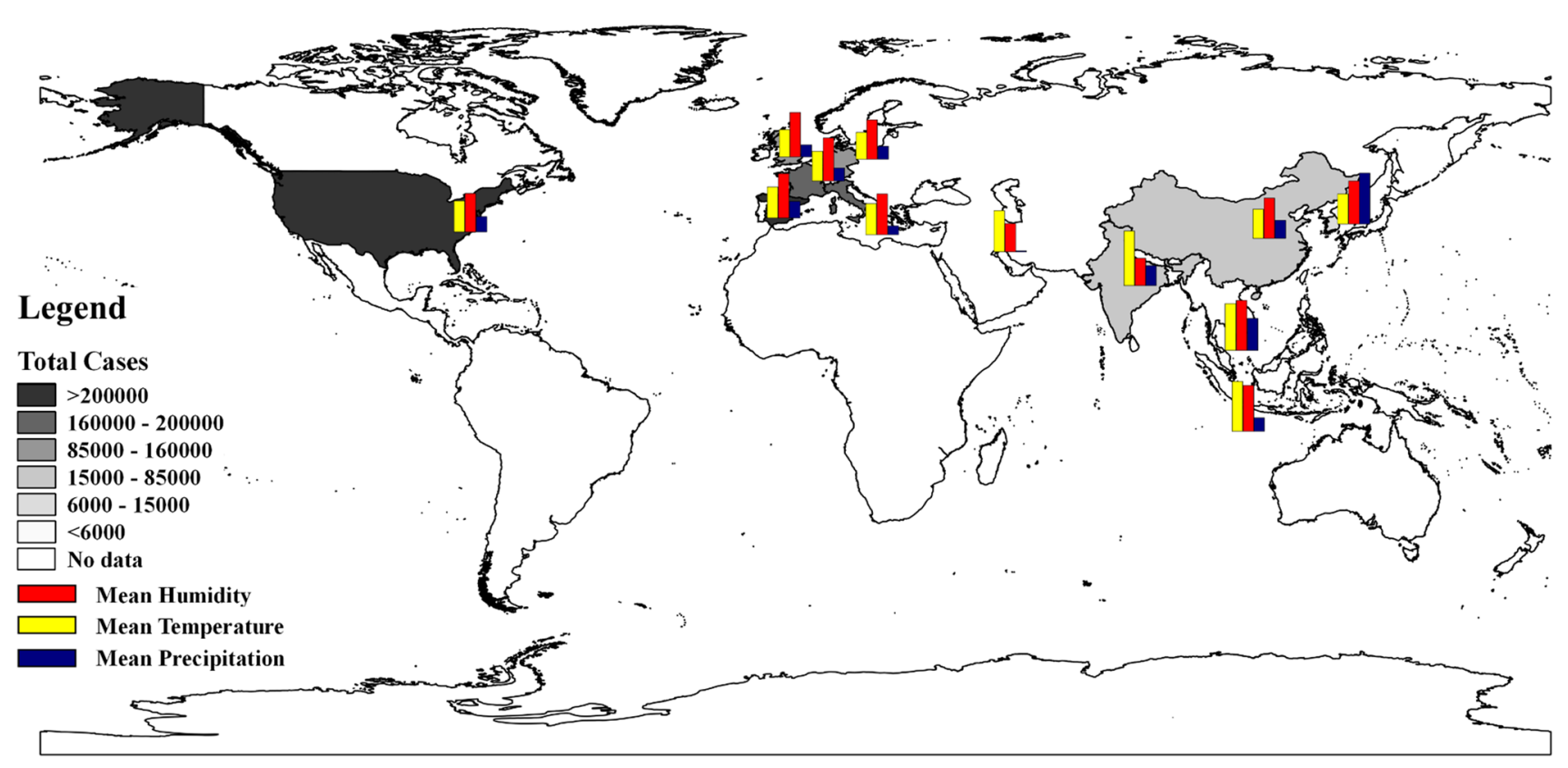

Fig. 3 Spatial variation of temperature, humidity, precipitation, and total infected cases for the selected countries studied 
Fig. 4 Spatial distribution of temperature and humidity in relation to pandemic spread across the affected countries

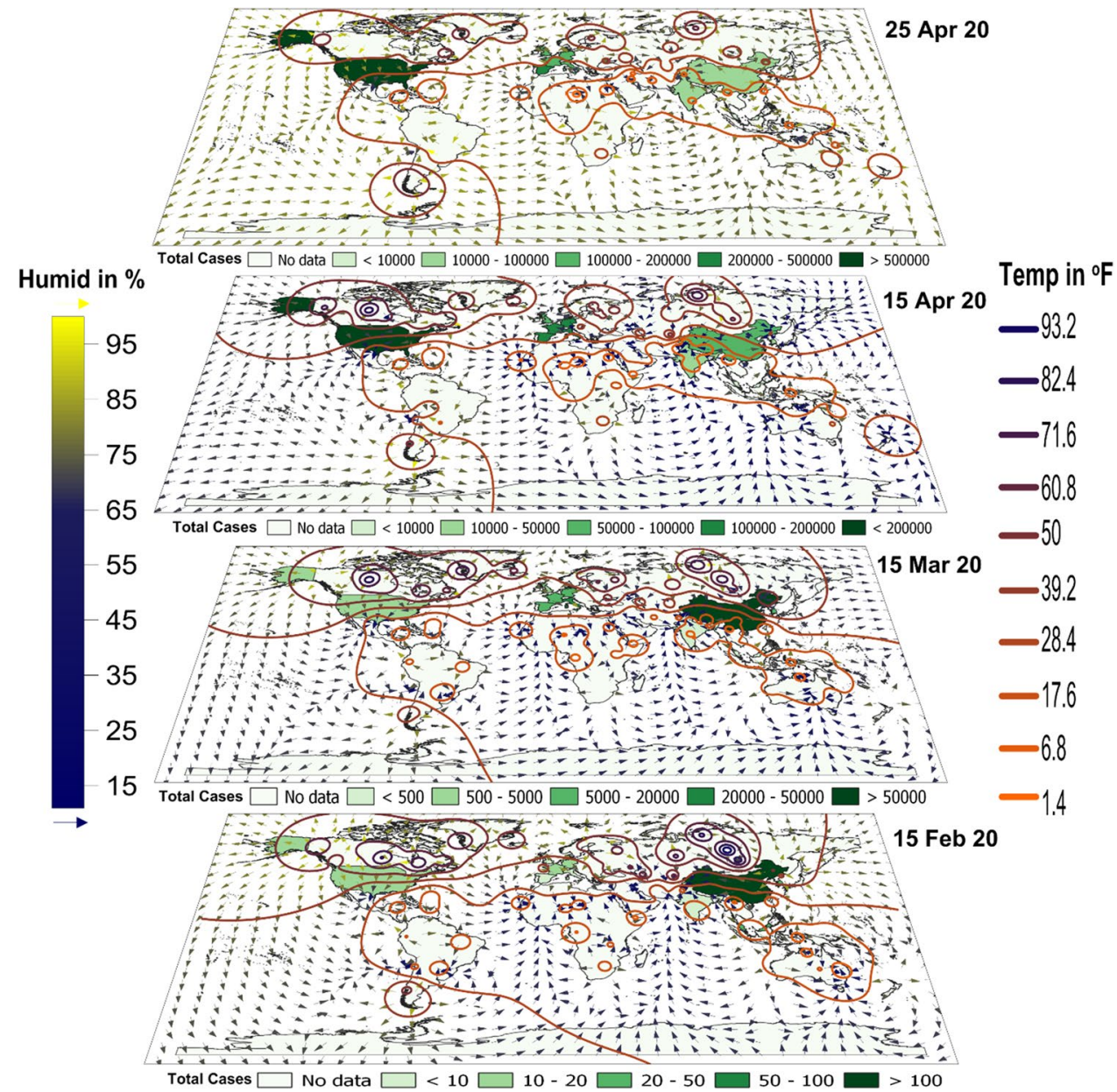

summer. Latitudinal variation in the distribution of oxygen is also observed with respect to season (Keeling et al. 1998; Keeling and Shertz 1992; Manning et al. 2003). $\mathrm{O}_{2}$ in the atmosphere is also influenced by two factors, namely $\mathrm{O}_{3}$ and UV (Olson et al. 2018). Although a conclusive interaction of these parameters is not observed, a general observation by Kasting and Donahue (2012) shows that $\mathrm{O}_{3}$ is also responsible for the oxygen-depleted atmosphere.

It is clear and evident that there has been a transformation and process of mutation reported from samples collected globally (Korber et al. 2020). Subsequently, the mutant forms show variation during the months of March and April. D614G mutation hints that the samples prior to March 1 were characteristically represented by the D614 form and there was a slow transition indicating the predominance of G614 during the 15th of March. The early pandemic spread in Europe was initiated by D614; later, G614 was represented in the samples from March, and it subsequently dominated in the first week of April. Similarly, samples from Asian countries also showed the same trend; prior to mid-March was dominated by D614 and later by G614. A few mutant forms like S943P was reported on the 13th of April in Belgium, A831V and D839/Y/N/E during April in Europe.

These transformations comply with the period of meteorological changes with respect to temperature, humidity, and precipitation. Prior to March 15, the northern hemisphere was predominantly $<40^{\circ} \mathrm{F}$ temperature and the western countries have humidity $>65 \%$ and $>85 \%$ in a few locations with no significant rain events. Subsequently, after March 15 , there was an increase in temperature of the Northern hemisphere with drastic variation in humidity. Temperature plays a key role in the state of the human immune system (Guo et al. 2011, 2016; Loh et al. 2013). The sudden variation in the rapid increase in respiratory mortality is due to an abrupt large variation in temperature (Zhan et al. 2017). Hence, on this baseline, the frequent unstable meteorological conditions act as a supplementary factor for the CoV-2 spread.

The mutant form of G614 was observed to dominate D614 in different time periods and meteorological conditions: During March 1-10, it was observed to dominate in China, Italy, and France; during 11-20 March in the USA, Germany, Spain, and Kuwait; later during March 21-31 in 
the UK; and April 1-10 in Singapore (Korber et al. 2020). The data of the remaining countries like India and Malaysia was not accessible, whereas South Korea had reported only one variant (D614) prior to March. The time series variation of the temperature, humidity, and precipitation was compared in relation to the mutation forms (Supplementary Fig. S4). The values of these meteorological parameters observed during the predominance of G614 in various countries (Table 3) show that a temperature range of $43^{\circ} \mathrm{F}$ to $54^{\circ} \mathrm{F}$ and a humidity of $67-75 \%$ along with precipitation $2-4 \mathrm{~mm}$ was inferred to be optimum for the transition of this mutant form from D614 to G614. However, the optimum ranges varied at extreme weather conditions in countries like Kuwait (high temperature and low humidity), Singapore (high temperature and high humidity), and France (higher humidity and precipitation) during the study period.

The regional variations in meteorological parameters could have resulted in L8V/W in Hong Kong, H49Y in China, and recombination form of S943P in Belgium (Rehman et al. 2020). An 81 nucleotide deletion in ORF7a of CoV-2 was identified (Holland et al. 2020), leading to the inference that the virus may become weak and finally extinct. Irrespective of the changes in these facts, the changes in the mutant forms of $\mathrm{CoV}-2$ were inferred to be chiefly influenced by global or local meteorological parameters apart from other factors. Attempts have also been made to understand mortality due to COVID-19 by comparing premorbid conditions in relation to smoking habits with meteorological parameters. WHO report (2017) shows that among the countries considered for this study, western nations including China had more smokers. An overlay of meteorological parameters (temperature and humidity) with the mortality rate of smokers shows that mortality in western countries was favored by lower temperatures and higher humidity (Fig. 5).

We strongly emphasize the importance of proper quarantine measures in spite of hot, humid regions where incidence rates appear to be lower to effectively reduce COVID-19 phase 1 transmission and protect society from the resulting risks. Hot weather alone may not control the spread of COVID-19. Even in hot and humid countries, if proper safety measures are not followed, COVID-19-positive cases continue to increase. In addition to weather, there are other factors that may play a role in the number of affected cases in a region, including population density, health policies, political and social structures, quality of healthcare, health care interventions, and global connectivity. Future studies could incorporate these factors and use an epidemiological, statistical model to understand the relationship between weather and COVID-19 transmission.

\section{Conclusion}

The study has attempted to understand the influence of meteorological parameters on the COVID-19 variables in the selected countries. Though the initiation of the pandemic varies in each country, the interval between the first
Table 3 Meteorological conditions during the predominance of G614 mutant form in different countries

\begin{tabular}{|c|c|c|c|c|c|c|c|c|c|}
\hline & \multicolumn{2}{|c|}{ March 1-10 } & \multirow[b]{2}{*}{ France } & \multicolumn{2}{|c|}{$\begin{array}{l}\text { March } \\
11-20\end{array}$} & \multirow[b]{2}{*}{ Germany } & \multirow[b]{2}{*}{ Kuwait } & \multirow{2}{*}{$\begin{array}{l}\text { March 20-30 } \\
\text { UK }\end{array}$} & \multirow{2}{*}{$\begin{array}{l}\text { April 1-10 } \\
\text { Singapore }\end{array}$} \\
\hline & China & Italy & & USA & Spain & & & & \\
\hline Temperature $\left({ }^{\circ} \mathrm{F}\right)$ & 47 & 50.5 & 46 & 52 & 54 & 47.9 & 70 & 43.3 & 84.9 \\
\hline Humidity (\%) & 67.8 & 72.6 & 82 & 69 & 75 & 75 & 45.7 & 69.6 & 72.3 \\
\hline Precipitation $(\mathrm{mm})$ & 3.3 & 3.4 & 5.5 & 2.79 & 3.3 & 3.3 & 0.05 & 0.15 & 2.27 \\
\hline
\end{tabular}

Fig. 5 Comparison of premorbid condition (smoking habit) with the meteorological parameters

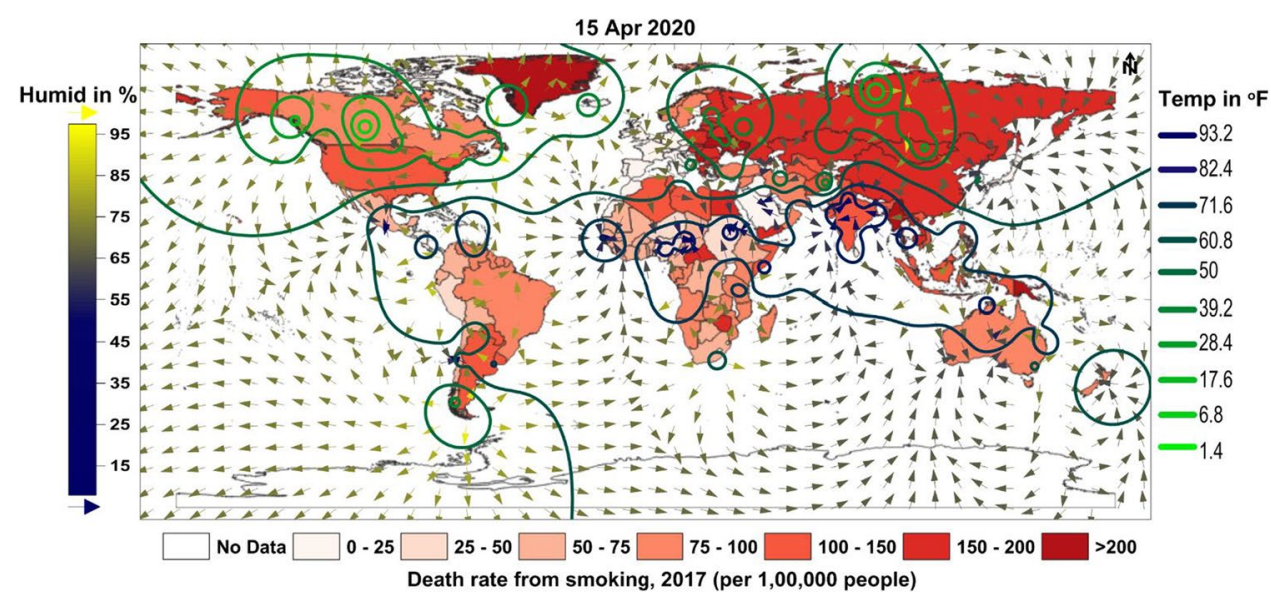


case and the movement restriction period has played a significant role in the spread. There has been an increase of the total cases in the Asian countries with the increase of the lapse time, and relatively no significant variation was observed in the western countries. The pandemic spread has not reflected any positive relation to population density in the western countries though the cases increased with density in Asian countries. It could be more generalized that the pandemic spread in the Asian countries are more influenced by the decrease in humidity though an increase of temperature played a key role irrespective of the geographical distribution; still, the interplay of multiple factors was more observed in the Asian countries. The daily death cases are more influenced by a decrease in humidity, precipitation, and wind in the European countries, the UK, and the USA. Hence, the complex interplay of the meteorological factors in the western countries was observed to influence daily mortality. The pandemic spread increased with an increase in temperature and a decrease in precipitation in all the countries. Though there was no significant precipitation observed in the study period in all the countries, the time series analysis shows the impact of this meteorological parameter on the daily death cases. The study has also concluded that the pandemic spread is more favored when temperature ranged from 45 to $55^{\circ} \mathrm{F}$, humidity from 65 to $75 \%$, and low precipitation conditions. It is also inferred that though South Korea has a favorable temperature and humidity toward the COVID-19 spread but the amount of precipitation has aided a decrease in the number of infected cases. The global spatial variation in temperature and humidity reveals that the countries reported with more infections of COVID-19 were represented in the regions with increased humidity and lesser temperature. The trend of variation of these two parameters during the study period has helped in the persistence of the virus globally. It is also postulated that the availability of oxygen was lesser in cold/winter regions, especially with respect to the latitudes, which has enhanced the impact of COVID-19 in western countries. Predominant mutant forms of CoV-2 and their transformation showed a clear relationship with the meteorological changes in Asian and European countries. Temperature range of $43-54^{\circ} \mathrm{F}$ and a humidity of $67-75 \%$ along with precipitation of 2-4 $\mathrm{mm}$ were inferred to be optimum for the transition of this mutant form from D614 to G614. More data on UV radiation, $\mathrm{O}_{3}$ levels, and $\mathrm{CO}_{2}$ and $\mathrm{O}_{2}$ concentration in the atmosphere would reveal a clearer picture of the pandemic spread. Hence, it is concluded from the study that higher temperatures, optimum humidity, and less precipitation serve as major meteorological factors governing the pandemic spread apart from social distancing and immune response of the community. Public isolation measures, herd immunity, migration patterns, population density, and cultural aspects may have a direct influence on the spread of this disease. Therefore, knowledge of weather conditions in the context of public health policy is of great value to humanity at this critical time.

Supplementary Information The online version contains supplementary material available at https://doi.org/10.1007/s11356-021-17481-8.

Author contribution SC: supervision, original draft, review editing, project administrator. MVP: original draft and editing. SV: data curation and editing, data validation, and software. KS: data validation and software. SDR: conceptualization, review and editing. GG: conceptualization and data curation. ALR: data validation and editing. PB: data validation and review and editing.

Data availability The datasets generated during and/or analyzed during the current study are available in the NASA website and worldometers repositories (https://power.larc.nasa.gov; www.worldometers.com).

\section{Declarations}

Ethics approval Not applicable.

Consent to participate Not applicable.

Consent for publication Not applicable.

Competing interests The authors declare no competing interests.

\section{References}

Alexander I (2019) Influence of weather and seasonal variations in temperature and humidity on super saturation and enhanced deposition of submicron aerosols in the human respiratory tract. Atmos Environ. https://doi.org/10.1016/j.atmosenv.2019.117226

Anthony VA, Elia MS, Judith H, Biggin T, Theodor DS (1986) Indirect health effects of relative humidity in indoor environments. Environ Health Perspect 65:351-361

Bagyaraj M, Shankar K, Alemayehu T, Muthukumarasamy R, Gnanachandrasamy G (2020) Distribution and trend analysis of COVID19 in India: geospatial approach. J Geographical Studies 4(1):1-9

Barreca AI (2012) Climate change, humidity, and mortality in the United States. Journal of Env Management 63:19-34

Barreca AI, Jay S (2012) Absolute humidity, temperature, and influenza mortality: 30 years of county-level evidence from the United States. Am J Epidemiol 176(7):114-122

Baumgartner EA, Dao CN, Nasreen S, Bhuiyan MU, Mah-E-Muneer S, Al Mamun A, Sharker MAY, Zaman RU, Cheng P-Y, Klimov AI et al (2012) Seasonality, timing, and climate drivers of influenza activity worldwide. J Infect Dis. 206:838-846. https://doi.org/10. 1093/infdis/jis467

Bu J, Peng D, Xiao H, et al. (2020) Analysis of meteorological conditions and prediction of epidemic trend of 2019-nCoV infection in 2020. medRxiv: 20022715v1: https://www.medrxiv.org/conte nt/; https://doi.org/10.1101/2020.02.13.20022715v1. Accessed 18 March 2020

Cascella M, Michael R, Arturo C, Scott C, Dulebohn, Raffaela Di, Napoli (2020) Features, evaluation and treatment coronavirus (COVID-19) - StatPearls - NCBI Bookshelf 
Chan JF, To KK, Tse H, Jin DY, Yuen KY (2013) Interspecies transmission and emergence of novel viruses: lessons from bats and birds. Trends Microbiol 21(10):544-555

Chen B, Liang H, Yuan X, Hu Y, Xu M, Zhao Y (2020) Roles of meteorological conditions in COVID-19 transmission on a worldwide scale. Med Rxiv. https://doi.org/10.1101/2020.03.16.20037168

Chen S, Prettner K, Kuhn M et al (2021) Climate and the spread of COVID-19. Sci Rep 11:9042

Chew MYL, Wong CW, Kang LH (1998) Building facades: a guide to common defects in tropical climates. world scientific 11:13-14

Chowell G, Cécile V, Lone S, Mark M, Wladimir JA (2010) The reproduction number of seasonal influenza epidemics in Brazil, 1996-2006. Proc Biol Sci 277(1689):1857-1866

D'Amato $\mathrm{M}$ et al (2018) The impact of cold on the respiratory tract and its consequences to respiratory health. Clin Transl Allergy. https:// doi.org/10.1186/s13601-018-0208-9

Dadbakhsh M, Khanjani N, Bahrampour A, Haghighi PS (2017) Death from respiratory diseases and temperature in Shiraz, Iran (20062011). Int J Biometeorol 61(2):239-246

Davis RE, Dougherty E, McArthur C, Huang QU, Baker MG (2016a) Cold, dry air is associated with influenza and pneumonia mortality in Auckland. New Zealand Influenza Other Respir Viruses 10(4):310-313

Davis RE, Mc Gregor GR, Enfield KB (2016b) Humidity: a review and primer on atmospheric moisture and human health. Environ Res 144:106-116

Deredec A, Courchamp F (2003) Extinction thresholds in host-parasite dynamics. Ann Zool Fenn 40:115-130

de Souza A, Fernandes WA, Pavão HG, Lastoria G, do Amaral Albrez E (2012) Potential impacts of climate variability on respiratory morbidity in children, infants, and adults. J Bras Pneumol 38(6):708-715

Donaldson GC, Seemungal T, Jeffries DJ, Wedzicha JA (2001) Effect of temperature on lung function and symptoms in chronic obstructive pulmonary disease. Eur Respir J. https://doi.org/10.1034/j. 1399-3003.1999.13d21.x

Easterling DR, Horton B, Jones PD, Peterson TC, Karl TR, Parker DE, Salinger MJ, Razuvayev V, Plummer N, Jamason P (1997) Maximum and minimum temperature trends for the globe. Science 277(5324):364-367

Fallah GG, Mayvaneh F (2016) Effect of air temperature and universal thermal climate index on respiratory diseases mortality in Mashhad. Iran Arch Iran Med 19(9):618-624

Ficetola GF, Rubolini D (2020) Climate affects global patterns of COVID-19 early outbreak dynamics. medRxiv. https://doi.org/ 10.1101/2020.03.23.20040501

Golshahi L, Longest PW, Azimi M, Syed A, Hindle M (2014) Intermittent aerosol delivery to the lungs during high-flow nasal cannula therapy. Respir Care 59(10):1476-1486

Gómez-Acebo I, Llorca J, Dierssen T (2013) Cold related mortality due to cardiovascular diseases, respiratory diseases and cancer: a case-crossover study. Public Health 127(3):252-258

Grasmeijer F, Grasmeijer N, Hagedoorn P, Frijlink HW, de Boer AH (2015) Recent advances in the fundamental understanding of adhesive mixtures for inhalation. Curr Pharm Des. https://doi. org/10.2174/1381612821666151008124622

Guo Y, Barnett AG, Yu W, Pan X, Ye X, Huang C, Tong S (2011) A large change in temperature between neighboring days increases the risk of mortality. PLoS ONE 6:16511

Guo Y, Gasparrini A, Armstrong BG, Tawatsupa B, Tobias A, Lavigne E, Coelho MS, Pan X, Kim H, Hashizume M, Honda Y, Guo YL, Wu CF, Zanobetti A, Schwartz JD, Bell ML, Overcenco A, Punnasiri K, Li S, Tian L, Saldiva P, Williams G, Tong S (2016) Temperature variability and mortality: a multi-country study. Environ Health Perspect 124:1554-1559
Gupta A, Pradhan B, Maulud KNA (2020) Estimating the impact of daily weather on the temporal pattern of COVID-19 outbreak in India. Earth Syst Environ 4:523-534. https://doi.org/10.1007/ s41748-020-00179-1

Haidari M, Muzammil A, Casscells SW, Madjid M (2007) Statins block influenza infection by down-regulating Rho/Rho kinase pathway. Circulation 116:116-117

Hicks BM, Filion KB, Yin H, Sakr L, Udell JA, Azoulay L (2018) Angiotensin converting enzyme inhibitors and risk of lung cancer: population based cohort study. BMJ 363:k4209

Holland L. A, Kaelin E. A, Maqsood R, Estifanos B, Wu L. I, Varsani A, Halden R. U, Hogue B. G, Scotch M, Lim E. S (2020) An 81 nucleotide deletion in SARS-CoV-2 ORF7a identified from sentinel surveillance in Arizona (Jan-Mar 2020). Journal of virology JVI.00711-20. https://www.ncbi.nlm.nih.gov/books/NBK55 4776/?report=printable1/16. Accessed 18 March 2020

Hu H, Nigmatulina K, Eckhoff P (2013) The scaling of contact rates with population density for the infectious disease models. Math Biosci 244(125): 134

Ji W, Wang W, Zhao X, Zai J, Li X (2020) Cross-species transmission of the newly identified coronavirus 2019-nCoV. J Med Virol 92:433-440. https://doi.org/10.1002/jmv.25682

Joseph MC, Lawrence JA, McGready John, Garry RC (2018) The relationship of lung function with ambient temperature. PLOS ONE. https://doi.org/10.1371/journal.pone.0191409

Kampf G, Todt D, Pfaender S, Steinmann E (2020) Persistence of coronaviruses on inanimate surfaces and their inactivation with biocidal agents. J Hosp Infect 104:246-251

Kasting JF, Donahue TM (2012) The evolution of atmospheric ozone, Journal of Geophysical Research. Oceans 85(C6):3255-3263

Keeling RF, Shertz SR (1992) Seasonal and interannual variations in atmospheric oxygen and implications for the global carbon cycle. Nature 358:723-727

Keeling RF, Stephens BB, Najjar RG, Doney SC, Archer D, Heimann $M$ (1998) Seasonal variations in the atmospheric $\mathrm{O}_{2} / \mathrm{N}_{2}$ ratio in relation to the kinetics of air-sea gas exchange. Global Biogeochem Cycles 12:141-163

Kim SS, Kim CH, Kim JW, Kung HC, Park TW, Shin YS, Kim JD, Ryu S, Kim W-J, Choi YH, Song KS (2017) Airborne particulate matter increases MUC5AC expression by downregulating Claudin-1 expression in human airway cells. BMB Rep 50:516-521

Korber B, Fischer W, Gnanakaran S, Yoon, H, Theiler J, Abfalterer W, Foley B, Giorgi EE, Bhattacharya T, Parker MD, Partidge DG, Evans CM, de Silva Ti, Labranche CC, Montefiori DC (2020) Spike mutation pipeline reveals the emergence of a more transmissible form of SARS-CoV-2. https://doi.org/10.1101/2020.04. 29.069054.

Kumberger PK, Frey F, Schwarz US, Graw F (2016) Multiscale modeling of virus replication and spread. Letters 590(13):1972-1986

Li R, Peter R, Bertrand MR (2018) Effect of population density on epidemics. Physica A 510:713-724

Linder FE, Grove RD (1947) Vital statistics rates in the United States, 1900-1940. National Office of Vital Statistics, Government Printing Office, Washington DC

Lindsley WG, Reynolds JS, Szalajda JV, Noti JD, Beezhold DH (2013) A cough aerosol simulator for the study of disease transmission by human cough-generated aerosols. Aerosol Sci Technol 47(8):937-944

Lisa MC, Soyoung J, William AR, David JW, Mark DS (2010) Effects of air temperature and relative humidity on coronavirus survival on surfaces. Appl Environ Microbiol 76(9):2712-2717

Liu J , Ji Z, Jinxi Y, Zhang X, Li L, Xiaocheng Xu, He X, Wang Bo, Shihua Fu, Niu T, Yan J, Shi Y, Ren X, Niu J, Zhu W, Li S, Luo B, Zhang K (2020) Impact of meteorological factors on the 
COVID-19 transmission: a multi-city study in China. Sci Total Environ 726:138513. https://doi.org/10.1016/j.scitotenv.2020. 138513

Loh E, Kugelberg E, Tracy A, Zhang Q, Gollan B, Ewles H, Chalmers R, Pelicic V, Tang CM (2013) Temperature triggers immune evasion by Neisseria meningitides. Nature 502:237-240

Ma Y, Zhao Y, Liu J, He X, Wang B, Fu S (2020) Effects of temperature variation and humidity on the mortality of COVID-19 in Wuhan. Sci Total Environ 724:138226. https://doi.org/10.1016/j. scitotenv.2020.138226

Ma Y, Zhao Y, Liu J, He X, Wang Bo, Shihua Fu, Yan J, Niu J, Zhou $\mathrm{Ji}$, Bin Lu (2020) Effects of temperature variation and humidity on the death of COVID-19in Wuhan. China Science of the Total Environment 724:138226. https://doi.org/10.1016/j.scitotenv. 2020.138226

Macfarlane A (1977) Daily mortality and environment in English conurbations. Air pollution, low temperature, and influenza in Greater London. Br J Prev Soc Med 31(1):54-61

Manning AC, Keeling RF, Katz LE, Paplawsky WJ, McEvoy EM (2003) Interpreting the seasonal cycles of atmospheric oxygen and carbon dioxide concentrations at American Samoa Observatory. Geophys Res Lett 30:1333. https://doi.org/10.1029/2001G L014312

Mecenas P, Bastos RTdRM, Vallinoto ACR, Normando D (2020) Effects of temperature and humidity on the spread of COVID-19: a systematic review. PLoS ONE 15(9):e0238339. https://doi.org/ 10.1371/journal.pone.0238339

Oliveiros B., Caramelo L., Ferreira N.C., Caramelo F. (2020) Role of temperature and humidity in the modulation of the doubling time of COVID-19 cases. medRxiv. https://doi.org/10.1101/2020.03. 05.20031872 .

Olson SL, Schwieterman EW, Reinhard CT, Ridgwell A, Kane SR, Meadows VS, Lyons TW (2018) Atmospheric seasonality as an exoplanet biosignature. Astrophys J. https://doi.org/10.3847/20418213/aac171

Perlman S, Netland J (2009) Coronaviruses post-SARS: update on replication and pathogenesis. Nat Rev Microbiol 7(6):439-450

Petropoulos F, Makridakis S (2020) Forecasting the novel coronavirus COVID-19. PLoS ONE 15(3):e0231236. https://doi.org/10.1371/ journal.pone. 0231236

Poole L (2020) Seasonal influences on the spread of SARS-CoV-2 (COVID19), causality, and forecastability (3-15-2020). SSRN Electron J. https://doi.org/10.2139/ssrn.3554746

Qasim B, Massaro JM, D’Agostino RB, Khan Sr S (2020) Effects of weather on coronavirus pandemic. Int J Environ Res Public Health. 17(15):5399. https://doi.org/10.3390/ijerph17155399

Qi H, Xiao S, Shi R, Ward MP, Chen Y, Tue W, Qing Su, Wang W, Wang X, Zhang Z (2020) COVID-19 transmission in Mainland China is associated with temperature and humidity: a time-series analysis. Sci Total Environ 728:138778. https://doi.org/10.1016/j. scitotenv. 2020.138778

Rehman S, Sharique L, Ihsan A, Liu Q (2020) Evolutionary trajectory for the emergence of novel coronavirus SARS-CoV-2. Pathogens 9:240

Sajadi M.M, Habibzadeh P, Vintzileos A, Shokouhi S, Miralles-Wilhelm F, Amoroso A (2020) Temperature and latitude analysis to predict potential spread and seasonality for COVID-19. Available at SSRN 3550308. https://doi.org/10.2139/ssrn.3550308

Sarangapani R, Wexler AS (1996) Growth and neutralization of sulfate aerosols in human airways. J Appl Physiol 81(1):480-490

Shaman J, Goldstein E, Lipsitch M (2011) Absolute humidity and pandemic versus epidemic influenza. Am J Epidemiol 173:127-135
Shaman J, Kohn M (2009) Absolute humidity modulates influenza survival, transmission, and seasonality. Proc Natl Acad Sci 106:3243-3248

Sharafkhani R, Khanjani N, Bakhtiari B, Jahani Y, Tabrizi JS, Tabrizi FM (2019) Diurnal temperature range and mortality in Tabriz (the northwest of Iran). Urban Clim 27:204-211. https://doi.org/10. 1016/j.uclim.2018.11.004

Shi P, Dong Y, Yan H, Zhao C, Li X, Liu W, He M, Tang S, Xi S (2020) Impact of temperature on the dynamics of the COVID-19 outbreak in China. Sci Total Environ 728:138890. https://doi.org/10.1016/j. scitotenv.2020.139051

Sobral M, Falcão F, Duarte GB, Sobral AIGP, Marinho MLM, Melo AS (2020) Association between climate variables and global transmission oF SARS-CoV-2. Sci Total Environ 729:138997. https://doi.org/10.1016/j.scitotenv.2020.138997

Tang X, Wu C, Li X, Song Y, Yao X, Wu X, Duan Y, Zhang H, Wang Y, Qian Z, Cui J, Lu J (2020) On the origin and continuing evolution of SARS-CoV-2. Natl Sci Rev. https://doi.org/10.1093/nsr/ nwaa036

Thivya C, Chidambaram S, Thilagavathi R, Prasanna MV, Singaraja C, Adithya VS, Nepolian M (2015) A multivariate statistical approach to identify the spatio-temporal variation of geochemical process in a hard rock aquifer. Environ Monit Assess 187:552. https://doi.org/10.1007/s10661-015-4738-5

Vasanthavigar M, Srinivasamoorthy K, Prasanna MV (2013) Identification of groundwater contamination zones and its sources by using multivariate statistical approach in Thirumanimuthar sub-basin, Tamil Nadu, India. Environ Earth Sci 68:1783-1795

Vitkina T, Veremchuk LV, Mineeva EE, Gvozdenko TA, Antonyuk MV, Novgorodtseva TP, Grigorieva EA (2019) The influence of weather and climate on patients with respiratory diseases in Vladivostok as a global health implication. Journal of Environmental Health Science and Engineering. https://doi.org/10.1007/ s40201-019-00407-5

Wang Y, Wang Y, Chen Y, Qin Q (2020) Unique epidemiological and clinical features of the emerging 2019 novel coronavirus pneumonia (COVID-19) implicate special control measures. J Med Virol 92:568-576

Wu Y, Jing W, Liu J, Ma Q, Yuan J, Wang Y, Du M, Liu M (2020) Effects of temperature and humidity on the daily new cases and new deaths of COVID-19 in 166 countries. Science of the Total Environment 729:139051

Xi J, Kim J, Si XA, Corley RA, Kabilan S, Wang S (2015) CFD modeling and image analysis of exhaled aerosols due to a growing bronchial tumor: towards non-invasive diagnosis and treatment of respiratory obstructive diseases. Theranostics 5:443-455

Yan R, Zhang Y, Yaning Li Lu, Xia YG, Zhou Q (2020) Structural basis for the recognition of SARS-CoV-2 by full-length human ACE2. Science 367(6485):1444-14448

Zhan Z, Zhao Y, Pang S, Zhong X, Wu C, Ding Z (2017) Temperature change between neighboring days and mortality in United States: a nationwide study. Sci Total Environ 584:1152-1161

Zhang Y, Peng L, Kan H, Xu J, Chen R, Liu Y, Wang W (2014) Effects of meteorological factors on daily hospital admissions for asthma in adults: a time-series analysis. PLoS ONE 9(7):e102475. https:// doi.org/10.1371/journal.pone.0102475

Publisher's Note Springer Nature remains neutral with regard to jurisdictional claims in published maps and institutional affiliations. 